\title{
A Child's Right to Early Childhood Education in Emergency Contexts
}

\author{
Aurelia Di Santo, PhD \\ Associate Professor \\ School of Early Childhood Studies \\ Ryerson University \\ disanto@ryerson.ca
}

\author{
Katie-Jay Scott \\ Executive Director \\ iACT \\ ktj@iactivism.org
}

\begin{abstract}
This paper presents an early childhood education model that upholds a child's right to education in one of the world's most vulnerable and forgotten communities: a refugee camp. iACT, a nongovernmental organization, works directly with refugee beneficiaries to establish, adapt, and implement Little Ripples, an early childhood education program laying the foundation for a lifetime of well-being, learning, health, and peace for children affected by displacement and violence. This paper explores how iACT invests in the capacity of refugee community members to provide an early learning program that exceeds global standards for child-friendly spaces and the nurturing care model by prioritizing children's rights.
\end{abstract}

Keywords: children's rights, refugee children, early learning curriculum, early childhood education in emergencies, refugee-led programs 


\section{Introduction}

In the modern era, we are witnessing the displacement of millions of children forced from their homes as a result of conflict and violence. United Nations High Commissioner for Refugees (UNHCR) (2019) reports that there are over 25 million refugees worldwide, of which over 50\% are children, age 18 and younger. Accompanied, unaccompanied, and separated children are fleeing conflict zones and seeking refuge in neighbouring countries. While they are escaping atrocious living conditions in their home country, millions of these children continue to face insecurities and deplorable and alarming conditions in temporary shelters, refugee camps, and detention centres. For instance, refugee children typically face months of uncertainty as their families await their food rations, lack access to clean water and health care, and contend with violence and unexpected uprisings. All of these factors severely impact many of their rights as outlined in the Convention on the Rights of the Child (UNCRC) (Convention on the Rights of the Child, 1989). The violation of UNCRC Article 28, the focus of this article, is the child's right

to education and specifically the right to early childhood education. In this article, we discuss the Little Ripples early childhood education curriculum (iACT, 2019), a unique cutting-edge program that is trauma-informed, empathy-based and, most importantly, led by the refugee communities in which the programs are located. The program aims to provide refugee children with access to consistent early learning in a space that supports their rights as children. Offering quality early learning programs in emergency contexts may serve as a catalyst for children to realize their other rights in ways that might not be possible if they were not enrolled in the program.

\section{The Right to Early Childhood Education in Emergency Contexts}

Since 1989, all but one United Nations Member States have ratified the UNCRC. Thus, all children, as rights-holders, have the right to education (see UNCRC Articles 28 \& 29). Although the right to early childhood education is not explicit in the UNCRC, according to the Committee on the Rights of the Child's (CRC) General Comment No. 7 (2005), Implementing Child Rights in Early Childhood, "the right to education during early childhood [begins] at birth and [is] closely linked to young children's right to maximum development" (p.13). As 
2020 Canadian Journal of Children's Rights

such, the CRC presents recommendations for "comprehensive policies and programs for early childhood" (2005, p.10). Furthermore, States Parties that have ratified the 1951 Convention relating to the Status of Refugees are expected to uphold, respect, and protect refugee rights (UNHCR, 2017). With respect to welfare, States "shall accord to refugees the same treatment as is accorded to nationals with respect to elementary education" (Convention relating to the Status of Refugees, art 22.1). The treaty recognizes the "undue heavy burdens on certain countries" (p.1); thus, the involvement of the international community is a must for realizing the rights of refugees. Irrespective of the host country's resources for offering early childhood education, the international community has a role in supporting children's early learning and development through quality care and education programs. Regardless of treaties such as the UNCRC, refugee families worldwide continue to lack the opportunity for their children to access early childhood education. For instance, refugee children living in camps face the critical issue of accessibility and early learning programs are rarely included in education funding initiatives. Although there is an increased awareness of the importance of early childhood development in emergency contexts, the needs of these young children are persistently overlooked (Miliband et al., 2018).

Children's access to early childhood education that offers quality play-based learning programs are ideal environments to support the healthy development of young children; the benefits are well documented in research (for example, see Bakken et al., 2017; OECD, 2016). Unfortunately, and to the determent of young refugee children, the provision of early childhood education is beyond the scope of legislation related to compulsory education (UNHCR, UNICEF, \& IOM, 2019) in emergency contexts. In fact, only $2 \%-4 \%$ of humanitarian funding is targeted for all types of education (Education Cannot Wait, 2020). Therefore, it is not surprising that early childhood education is excluded from program initiatives. As a consequence, very few young children living in refugee camps have access to educational programs until they reach school age. Sadly, this means that for many refugee children, their access to education is a right that continues to be violated by governments (Human Rights Watch, 2019). Ensuring "that all girls and boys have access to quality early childhood development, care and pre-primary education so that they are ready for primary education" is one of the targets of Goal 4 of the SDGs - ensuring "inclusive and equitable quality education and [promoting] lifelong learning opportunities for all” (United Nations, 2015). 'Theirworld's' (2016) pre-primary score card 
highlights the crucial role of donor governmental aid for education in realizing the Sustainable Development Goal (SDG) of universal access to early childhood education.

Existing early childhood education programs for displaced children tend to be offered by humanitarian aid groups and non-profit organizations. For instance, in 2017, the BRAC Institute of Educational Development, the largest international non-governmental organization, adapted their Play Lab program for Rohingya refugee children from birth to age six who are living in emergency contexts located in Cox's Bazar, Bangladesh. BRAC provides child-friendly spaces where young children can participate in a play-based program (BRAC, 2020). In February 2020, Sesame Street partnered with BRAC to offer Ahlan Simsim, a play-based program to children living in Cox's Bazar. Ahlan Simsim is a combination of a "new show and in-person direct services featuring storybooks, educational materials and caregiving-facing programming" (Sesame Workshop, 2019). Similarly, Sesame Street also partnered with International Rescue Committee to offer the program to Syrian refugee children across the Middle East. With funding from the MacArthur Foundation and Lego Foundation, Sesame Street is using mass media to offer the largest early childhood intervention program in the history of humanitarian response (Westin, 2019). Although this is a significant milestone in offering play-based learning in response to the educational needs of young children, one must take into account the contexts of refugee populations who, more often than not, live in camps with minimal resources and limited or no access to internet, cell phones, and electricity. This raises the crucial question of the replicability of the technology-based component of a children's program in many of the camps that are located in low-resourced countries.

UNICEF, an inter-governmental organization, has built and equipped 54 kindergarten classrooms for Syrian refugee children living in Jordan's Za'atai and Azraq refugee camps. In addition to building the classrooms, kindergarten teachers receive training in the area of inclusive education to support the right to education for all children, including children with disabilities (UNICEF, 2019). The UNICEF programs, however, do not include programming for children prior to the start of school. Other international non-government organizations working in emergency contexts that offer early childhood development or child well-being programming, albeit in a limited capacity, include but are not limited to Save the Children, International Rescue Committee, and Catholic Relief Services. Thus, it is reasonable to argue that overall, children who are living in emergency contexts have not had their right to early childhood education 
2020 Canadian Journal of Children's Rights

upheld by member States who have ratified the UNCRC and agreed to a child's right to education, specifically early childhood education. This crucial gap and violation of the right to early childhood education is being taken up by iACT, an international non-governmental organization.

\section{iACT's Little Ripples Early Childhood Education Program for Refugee Children}

\section{iACT's Beginnings}

In 2005, Gabriel Stauring travelled to refugee camps in eastern Chad to gather and amplify the stories of displaced Darfuris who had been affected by the genocide in Darfur, Sudan. Based on his work, Stauring founded iACT, which originally stood for interactive-activism, and encouraged global online engagement through his videos, actions, and a comment thread that he posted daily while visiting Darfuri refugees. Since 2005, iACT has worked alongside refugee communities and has formed trusting relationships with them. One member of the refugee community has shared that "iACT is the more trustful organization for us as refugees. We feel like we are studying leadership, ethics, transparency, integrity, and human rights" (Camp Goz Amer, Chad). iACT's approach involves listening, co-creating, connecting, creating a safe space for refugees to lead, and providing ongoing support. In doing so, they have striven to identify and address gaps in humanitarian programming. iACT utilizes innovative thinking, a humancentred design process, and collaborative relationships to create programs that are based on the needs identified and requested by Darfuri refugees. By asking the Darfuri refugee people what services they needed, iACT came to understand the need for programs that support young children's learning. This was the beginning of the Little Ripples program for preschool-age children. Since its inception in 2013, Little Ripples is now offered in multiple refugee camps in Chad, Cameroon, Greece, and Tanzania, and for internally displaced communities in the Central African Republic.

iACT has risen to the challenge to provide "humanitarian action to aid, empower, and extend hope to those affected by mass atrocities" (iACT, 2015). Guided by such organizational values as accountability to communities, empowerment, trust, and innovation, iACT has worked alongside more than 875 refugee leaders to meet the immediate needs of their own communities 
who have been forced to flee violence, conflict, and war zones. iACT's humanitarian action focuses on three main areas: early childhood programming, leadership development and human rights, and sports. In addition to early childhood education programs, iACT, in partnership with Darfuri refugees in eastern Chad, has developed and implemented LEAD with EMPATHY, a leadership development and human rights curriculum for the Little Ripples education directors and teachers. The overarching goal of the LEAD with EMPATHY peer-led curriculum is to provide teachers with opportunities to realize their full potential and capacity to be the leaders they aspire to be. It aims to accomplish this by fostering and strengthening the skills teachers need to manage and lead all aspects of the Little Ripples program in their community and for them to identify and lead activities and actions such as livelihood solutions that directly support their community's daily needs and the early childhood education program.

iACT has also implemented the Refugees United Soccer Academy (Academy). The Academy offers refugee children a safe place to play, move, and heal so as to realize their own power under the leadership and guidance of trained and employed refugee coaches who teach the children soccer, peacebuilding, and health skills. The Academy is available in five refugee camps serving up to 10,000 girls and boys ages six to thirteen (https://www.iact.ngo/impact/).

This article focuses on iACT's goal to work with and alongside refugee communities to "increase the human rights knowledge and leadership capacity of refugees to be changemakers in their communities" (iACT, 2020) so as to prioritize the child's right to early childhood education in emergency contexts. It details the collaboration with Darfur refugees who have been living in refugee camps in eastern Chad since the onset of the genocide in 2003 and who are unable to return home to Sudan or officially resettle in Chad. Many of the teachers and leaders involved in the early childhood education program originally fled mass atrocities in Sudan as adolescents or young adults; the majority of the children who attend the program were born in the refugee camps.

\section{Little Ripples Early Childhood Education Program}

In 2013, iACT launched the Little Ripples Early Childhood Education Program (LR) in refugee camps located in eastern Chad. This refugee-led program is an early learning program that meets the complex needs of children ages three- to five-years of age living in emergency contexts. To date, families have not identified a need for programs for their infants and toddlers; therefore, the LR program has focused on preschool-age children. With the knowledge that 
refugee children have encountered loss on multiple levels (e.g., their home, community, family and friends through separation and death, culture, access to education), that they are shaped by their experiences in displacement, and that the constant exposure to traumatic events result in continuous high levels of stress for the child, the LR program addresses a child's overall development and health and well-being. It is grounded in play-based education, trauma-recovery approaches, and restorative practices, and incorporates social and emotional learning, empathy development, positive behaviour management, peacebuilding, and mindfulness. Since 2013, 12,892 children have participated in a LR program offered in 56 classrooms/centres in five countries. LR programs are cost-effective and replicable, which are important factors as the program may be offered in diverse emergency settings that may be low on resources. To work towards ensuring that as many refugee children as possible realize their right to access early childhood education, iACT consistently explores ways of scaling up the program within the current refugee camp settings and partnering to expand the program into new emergency contexts. This scaling up initiative began within the first year of operation when the community informed iACT that children had trouble accessing the school-based LR program because of the distance between their compound and the school (these are large refugee camps), especially for such young children. Additionally, building large structures is costly and unsustainable. Thus, iACT and the community members co-created the Little Ripples home-based early learning programs, referred to as Ponds. In 2014, the first Pond program in a refugee camp located in Chad opened its doors to welcome 45 children into a new space for early learning.

To address the issue of accessibility and safety, the Pond programs are offered in family homes as they are ideal sites for offering early childhood education throughout the refugee camp. In keeping with iACT's philosophy, it is the community that identifies where in the camp the Pond programs are needed. Working in collaboration with the refugees, iACT staff visit potential host families who live in community-identified zones and who are interested in hosting the program. All interested families are interviewed and, if selected, they are asked for a three-year commitment to hosting a Pond in their home. Families who open up their home to the program are called Pond host families. Upon asking the mother of one Pond host family why she wanted to host the program, she said, "for the community, I wanted my house to be a pot of education." Homes, also referred to as compounds in the refugee camps in eastern Chad, are large spaces that may accommodate multiple generations of one family and often contain several small dwellings. 
All structures in a refugee camp are considered temporary. However, since the Darfuri refugee community has been living in camps in eastern Chad since 2003, all of the originally provided tents have given way to mud structures built from materials found in the environment. Each Pond home is retrofitted to create spaces that provide children with a safe and supportive early learning environment and must meet iACT's basic safety and well-being requirements. Pond homes must have a play space to accommodate 45 children, a fence surrounding the home, a shaded area so that children are protected from the sun, and access to water and a latrine. Homes that house a Pond program are retrofitted by the iACT team and refugee community leaders coming together to co-design and co-create the space. Figure 1 shows a children's shaded play area pre- and post-construction.

Figure 1: Pre-Construction and Post-Construction Shaded Play Area in a Pond Home
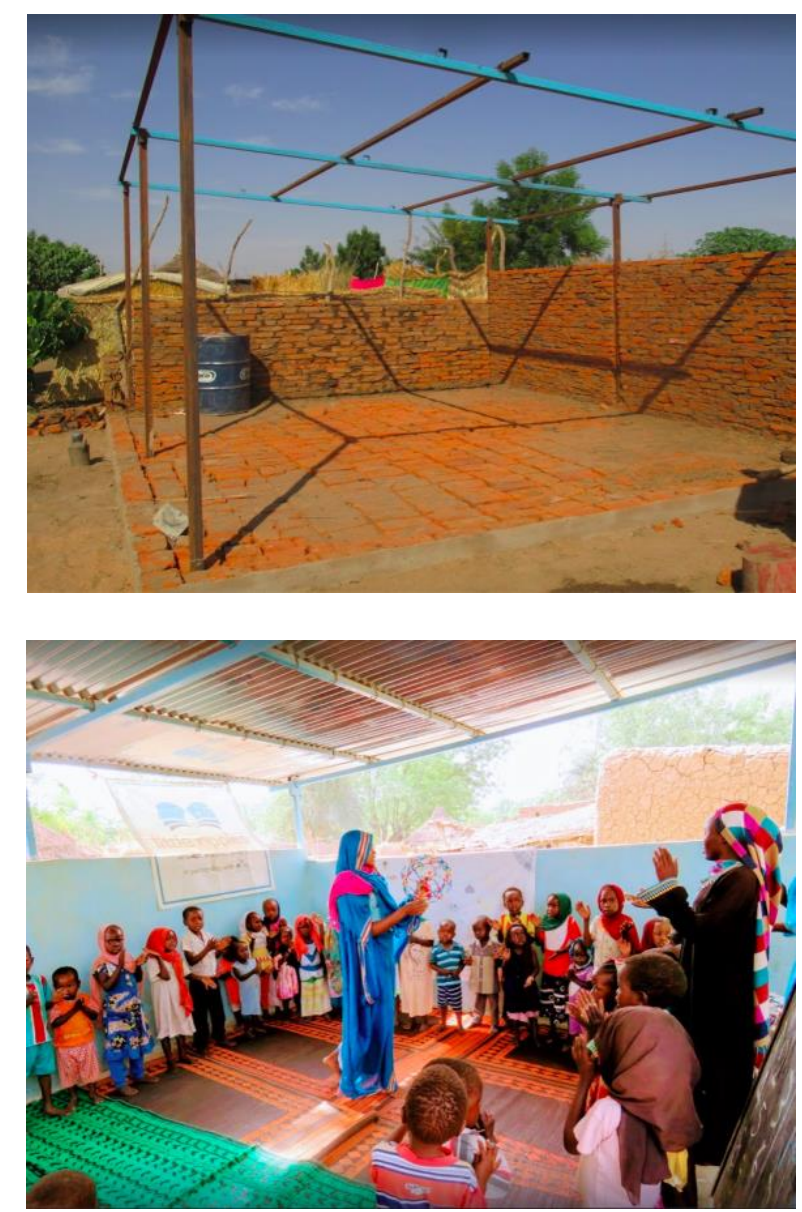

The LR curriculum is designed to reflect children's rights in its day-to-day practices and beyond the classroom. Children are acknowledged as active social beings who act upon their 
environment to learn and grow. Children spend their mornings in an emotionally and physically safe space that exceeds the globally recognized standard of a child-friendly space and have the opportunity to experience a reprieve from the hardships that they endure on a daily basis. Most LR children may not otherwise have time away from the stresses and trauma driven by their circumstances. One mother shared, "I feel very comfortable and restful that my child goes to Little Ripples and receives knowledge and play. Before attending Little Ripples, he would do nothing in the morning. He did not get any preschool education. He would just sit alone at home while I worked ... and did not like to share with others. Now he hugs people and he is much more sociable and sharing. He tells me about the songs and the games he does at school each day". Figure 2 shows children freely expressing themselves through movement.

Figure 2: Children's Right to Freedom of Expression - Moving Freely

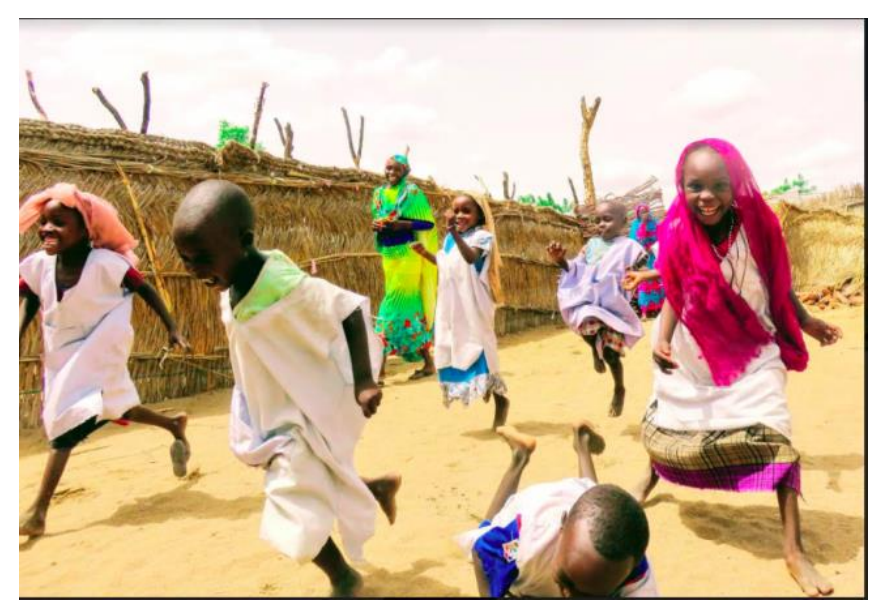

Although children have escaped conflict in their country of origin, refugee camps are generally not safe and secure spaces. As violence constantly looms over the community, food security is precarious and the withdrawal of aid as non-governmental agencies and donors move on to other emergencies results in daily adversities for the refugee community. To this end, Ponds offer preschool children a space where they can learn through play in a non-threatening setting while at the same time, exercise their other rights. Examples of these rights are presented in Table 1. 


\section{Table 1}

Examples of How LR Pond Programs Support Children's Rights

UNCRC Articles ${ }^{\mathrm{a}}$

A child's right to ...

\section{LR Pond Program Curriculum}

Article 2: non-discrimination

Article 3: best interests of the child

Articles 12 and 13: express views and freedom of expression

Article 24: attain the highest standard of health
The program does not discriminate against children-all children are included. All children in the household and team members' children who are not in the program but accompany their mothers to work are invited to eat the healthy meals and participate in the program. All children, no matter what language they speak or what their cultural background is, may enrol in the program.

As a trauma-informed and empathy-based curriculum, the program is intentionally designed to focus on the child's best interests.

Children are invited to participate in the program in ways that are comfortable for them and to use different modes of communication (e.g., art, movement, singing) to express themselves.

Children are encouraged to share their emotions and the educators are taught how to support a child and what they are feeling rather than trying to change it thus creating a safe environment for expression.

Pond programs ensure that children have access to clean water, soap, and a latrine. Children learn proper hand washing techniques and coughing into their sleeve in order to limit the spread of germs. 


\section{Table 1}

Examples of How LR Pond Programs Support Children's Rights

UNCRC Articles $^{\mathrm{a}}$

A child's right to ...
LR Pond Program Curriculum
Article 27: attain an adequate standard of living

Article 29: holistic development
All children receive a healthy, nutritious meal which, for many children, is their only meal of the day.

The LR curriculum focuses on social and emotional learning, fostering peacebuilding, play, physical movement, and cognitive skills (e.g., literacy, numeracy).

Children are introduced to appropriate mindfulness activities that they can draw on when faced with stressful circumstances.

The LR curriculum incorporates a playbased approach to early learning.

Note. ${ }^{\text {a }}$ Convention on the Rights of the Child, 1989

The Pond program is designed to exceed the offering of what UNICEF (2009) terms as child-friendly spaces for preschool children. Children spend their time in a "safe and protective environment" (UNICEF, 2009, p. 4) that mitigates the dangers children face enroute to and from school, promotes health and hygiene practices, includes nutrition by offering healthy meals, ensures safety and protection by fencing the family's compound to keep unwanted animals out, and offers shade for protection from the elements. Over and above supporting the child's right to early childhood education by providing a physical space to house a program, the curriculum offered within these spaces is crucial for realizing the overall rights of children. To this end, the LR trauma-informed curriculum is designed to support children's holistic development (see Table 1, Article 29). 
One LR teacher shared with us that, at the beginning kids registered didn't attend but they started to see that we are happy teachers and we have mindfulness, songs, food, colours, shapes, sports, language, and numbers. Now, they come, and they talk to people. Kids at Little Ripples are not very well. One student just three-years-old, asks his friends to make a circle around him so he can sit in the middle and do mindfulness like at Little Ripples.

As a trauma-informed curriculum specifically designed to support preschool children's social and emotional learning, LR aims to provide a nurturing care environment that is grounded in three main pillars: peace, helping, and sharing. Nurturing care is defined by the World Health Organization (WHO) (p. 12, 2018) as "the set of conditions that provide for children's health, nutrition, security and safety, responsive caregiving and opportunities for early learning" and is fundamental to children's development (Britto et al., 2017; World Health Organization, 2018). WHO proposes five components of nurturing care, all of which are reflected in the LR curriculum thus ensuring an environment that supports children's developmental potential. Refer to Table 2 for a description of the WHO's components and corresponding LR curriculum component.

\section{Table 2}

Nurturing Care Components and the LR Curriculum

$\begin{array}{ll}\text { Nurturing care components } & \text { LR curriculum }\end{array}$
attitudes towards, and beliefs about, children and childhood, implementing positive behaviour management strategies in the classroom, and understanding the importance of hygiene such as proper hand washing. Children participate in a play-based program that supports young children's learning and reduces their stress as they learn in an appropriate way as opposed to a traditional didactic teaching approach. 


\section{Canadian Journal of Children's Rights}

The curriculum offers both large- and smallgroup activities and children also have opportunities to self-select their activities. Programs in different camps may have different start times in order to ensure that children and families have access to the program.

\section{Table 2 (continued)}

Nurturing Care Components and the LR Curriculum

Nurturing care components ${ }^{\mathrm{a}}$

LR curriculum

Good health

Good nutrition

Responsive caregiving

Security and safety
Children's overall health is monitored daily and documented by the educators. In addition, children's anthropometric measurements are taken when assessing program effectiveness. Educators are responsive to children's needs and ensure that the daily activities are child focused. Hygiene practices are included in the daily program and children are encouraged to practice hygiene at home (e.g., coughing or sneezing into the elbow).

Food security is unpredictable and as such children receive a healthy meal every day that is prepared by the two Pond cooks. Furthermore, iACT and the refugee community leaders develop livelihood solutions that help support the Pond meal program.

As an outcome of their training, educators come to understand the importance of forming trusting relationships with all the children. They also foster positive social relationships between and among children.

Pond programs are child-friendly spaces and ensure a consistent daily routine for children's psychological stability. 


\section{LR Curriculum: Educator Training and Children's Rights}

iACT's LR curriculum objective is two-fold: 1) to ensure that a child's right to early childhood education is realized through the creation of home-based Pond programs, and 2) to support refugee women, no matter their educational background, in learning about the LR curriculum and implementing a Pond program thus setting the stage for them to take on

leadership roles in their community. Each Pond is comprised of a four-member team of two educators and two cooks, all of whom live in the community. All members of the team must complete the LR training program prior to working in the program. Additionally, all cooks must complete a health and hygiene training program. Given that this is a refugee-led initiative, community leaders are responsible for inviting potential educator candidates to participate in a LR program information meeting with the iACT team. Participants are then invited to choose whether they would like to attend the training sessions. From the pool of candidates who attend the training, Pond educators and cooks are hired by members of the iACT team in collaboration with community refugee leaders. The goal is for the hiring process to eventually be undertaken by the refugee community leaders, educators, and cooks; this has happened in at least two camps in eastern Chad after two LR team members were resettled to another country. This reflects iACT's intent for LR to become fully refugee- and community-led in order to build long-term capacity and program sustainability.

Educator training occurs approximately every six to eight months for a total of three sessions. Timing is context dependent as conflicts and climate (e.g., rainy season) play a role in determining when sessions will be offered. Although the LR curriculum is a pre-established framework, it is intended to be used as a guide and to be adapted to the needs and culture of the children in the community. Sessions are designed to be experiential and participatory so as to lay the foundation for the educators' classroom practice. iACT facilitators model classroom strategies which is key to educator candidates understanding the philosophy that frames the LR curriculum (see Figure 3). 


\section{Figure 3}

Training Workshop
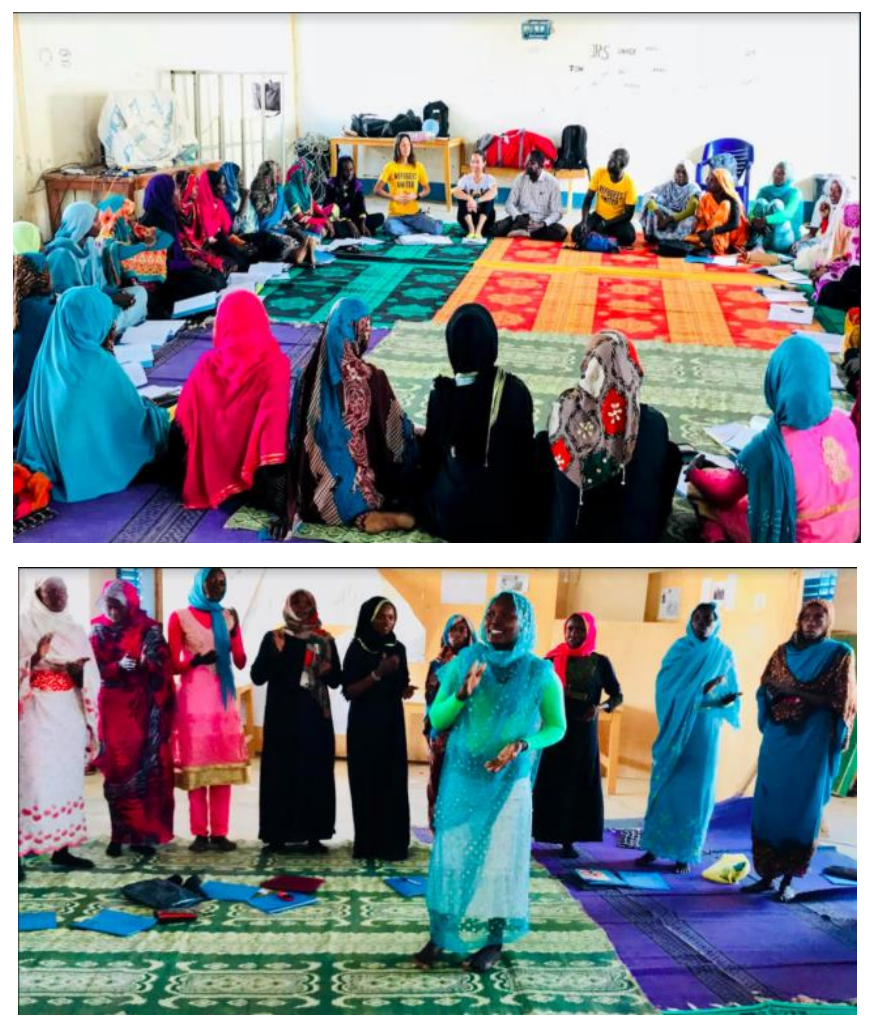

Top photo: An iACT facilitator leading a session.

Second photo: An educator candidate leading a session.

Infused throughout the curriculum and emphasized throughout the training are the core pillars of the LR curriculum of peace, helping, and sharing. Developing hope through the core pillars is one way that the educators can work towards positive change in the children's lives. The pillars also guide educators as they implement a rights-informed classroom practice. Growing up amid the chronic stresses of displacement and poverty can result in lowered expectations about the future. To address this issue, children enrolled in a Pond program receive an education that emphasizes living a "responsible life in a free society, in the spirit of understanding, peace, tolerance, equality of sexes, and friendship among all peoples, ethnic, national and religious groups and persons of indigenous origin" (Convention on the Rights of the Child, Article 29 (d), 1989). 
Implementing the LR curriculum in the Pond programs aims to create physically and emotionally safe and calming learning spaces for children by using language and management strategies that are grounded in strength-based teaching, inclusion, mindfulness, and non-violence (peace). One teacher shared that the "training has impacted me as teacher and woman. We have learned a new, positive way of dealing with our students. Before we were negative.... Now we learned to not be harmful. We learned to speak with a child and be at their level when speaking with them peacefully." Additionally, the curriculum fosters helping by creating positive personal relationships between and among children, educators, and the community while forming a culture of empathy, teamwork, and collaboration. Operating in communities with very limited resources, the LR curriculum promotes, demonstrates, and teaches sharing with and amongst the children, educators, and the community. These core pillars work in tandem with rights-informed practices. Several examples include the right to non-discrimination by supporting inclusion and forming a culture of empathy; ensuring the best interests of the child is paramount through creating learning spaces that are calm, peaceful, and safe; taking educational measures to protect children from all forms of abuse by advocating for a strengths-based approach to guiding children's behaviour and supporting their self-regulation; ensuring children are exposed to storybooks and visual materials (e.g., posters) that are written in their language and appropriately reflect their culture; and disseminating information for children's, families, and the community's health and well-being (e.g., COVID-19 resources). Moreover, Pond programs support the child's right to humanitarian aid and, in view of the fact that Ponds are co-created by the refugee community and programs are refugee-led, it is highly likely that they will be sustained over time.

To ensure a rights-informed practice, it is crucial that rights frame the LR curriculum and educator training. All educators and cooks attend sessions that are based on the following topics: 1) the importance of play-based learning for young children; 2) social and emotional learning; 3) peacebuilding; 4) mindfulness; 5) health and hygiene; and 6) employing a strengths-based approach for behaviour guidance and classroom management, and restorative practices. iACT team members model respect for others (adults and children), listening to others 'ideas and viewpoints, working collaboratively when developing children's activities, and actively participating in activities. They also create a safe space for the educators and cooks to share their ideas, challenges, and perspectives with regards to the program. Through modelling these 
2020 Canadian Journal of Children's Rights

strategies, the hope is that the educators will implement them in their classroom practice with the children. The following quotes highlight the LR teachers' engagement with the activities during the Little Ripples Teacher Training 1 workshops and what they enjoyed about the training:

${ }^{i}$ Aisha: Group work with [my] peers, being able to actually practice what [we] were learning with [our] peers, and mindfulness.

Farha: Mindfulness. The welcome circle, introductions and have the time and space to tell stories about yourself. Sitting in circle during training was new, [we]'ve never done that before. Participating and learning with other women.

Adam: In the beginning, the training seems difficult but the more we practiced, the more it all became very clear and easy. We learned a new method of teaching, a lot of information, things that are very different and we never knew before.

During the school year, educators in the community come together on a weekly basis to reflect on their practice and to exchange ideas. This reflective meeting is used as a time to support one another and to build their confidence and esteem as they gain classroom experience. Educators share resources with one another and have currently implemented a switching model so that educators can spend time in different Ponds to observe how their colleagues are implementing LR in their space. As noted earlier, the educators and cooks, in collaboration with community leaders, have begun to plan recruitment and interviews for new hires. Muijs, West, and Ainscow (2010) suggest that this strategy, which they term as "sharing resources," is one of the goals for networking (p. 8). The networking group aims to support marginalized refugee women in their role as Pond educators and leaders in the community. As one refugee community leader shared, "we need to teach Little Ripples teachers their human rights. Slowly, slowly, if everybody knows a human is a human, then we will have peace.” As educators learn about human rights and children's rights, the more likely they will be to continue to engage with rightsbased school practices.

\section{Conclusion-The iACT Way}

iACT and the refugee communities collaborate and plan to continue to prioritize children's right to early childhood education by scaling up the Pond program. The process begins by iACT team members listening to the refugee communities and determining their unique and 
2020 Canadian Journal of Children's Rights

specific needs so that they can move towards co-creating new programs. Through connections with the global community, obtaining necessary resources, and inviting iACT advisory committee members to participate in the process, new programs begin to take shape. Providing on-going support to the refugee communities is key until such time that refugees feel empowered to take the lead in sustaining the program. This is the iACT model; this is the iACT way to support the child's right to early childhood education. 


\section{References}

Bakken, L., Brown, N., \& Downing, B. (2017). Early childhood education: The long-term benefits. Journal of Research in Childhood Education, 31(2), 255-269.

BRAC (2020). Humanitarian crisis management program. Retrieved from http://response.brac.net/wp-content/uploads/2020/03/Activity-update_HCMP_February2020.pdf

Britto, P.R., Lye, S.J., Proulx, K., Yousafzai, A.K., Matthews, S.G., Vaivada, T., PerezEscamilla, R., Rao, N., Ip, P., Fernald, L.C.H., MacMillan, H., Hanson, M., Wachs, T.D., Yao, H., Yoshikawa, H., Cerezo, A., Leckman, J.F., \& Bhutta, Z.A. (2017). Advancing early childhood development: from science to scale 2 : Nurturing care: promoting early childhood development. Lancet, 389, 91-102.

Convention Relating to the Status of Refugees, opened for signature 28 July 1951, https:// www.unhcr.org/ 5d9ed32b4

Education Cannot Wait. 2020. https://www.educationcannotwait.org/

Human Rights Watch. (2019). Bangladesh: Rohingya children denied education unlawful restrictions on schooling risk creating a lost generation. https://www.hrw.org/report/2019/12/03/are-we-not-human/denial-education-rohingyarefugee-children-bangladesh

iACT. (2015). iACT: Facts, action, impact. https://www.iact.ngo

iACT. (2020). iACT: Education. https://www.iact.ngo/impact/\#education

Miliband, D.W., Smith, S., \& Murphy, K. (2018). Changing the humanitarian system for young children living in conflict and crisis. Early Childhood Matters. https://earlychildhoodmatters.online/2018/changing-the-humanitarian-system-for-youngchildren-living-in-conflict-and-crisis/

Muijs, D., West, M., \& Ainscow, M. (2010). Why network? Theoretical perspectives on networking. School Effectiveness and School Improvement, 21(1), 5-26. https://doi.org/10.1080/09243450903569692

OECD. (2016). What are the benefits from early childhood education? Education indicators in focus, 42. OECD Publishing. https://doi.org/10.1787/5jlwqvr76dbq-en 
2020 Canadian Journal of Children's Rights

Sesame Workshop. (2019). Alhan Simsim: A groundbreaking Arabic sesame “welcome”. https://www.sesameworkshop.org/what-we-do/shows/ahlan-simsim

TheirWorld. (2016). A global call to action: Stop neglecting pre-primary education investments. http://s3.amazonaws.com/theirworld-site-resources/Reports/Theirworld\% 20Scorecard\%20-\%20Stop\%20neglecting\%20preprimary\%20education\%20investments\%20-\%20June\%202016.pdf UNHCR. (2017). Protecting refugees: Cyprus. https://www.unhcr.org/cy/wpcontent/uploads/sites/41/2018/05/UNHCR_Brochure_EN.pdf

UNHCR. (2019). Figures at a glance. https://www.unhcr.org/figures-at-a-glance.html

UNICEF. (2019). Best start to education for thousands of preschool children in Za'atari and Azraq refugee camps. https://www.unicef.org/press-releases/best-start-educationthousands-preschool-children-zaatari-and-azraq-refugee-camps

UNHCR, UNICEF, \& IOM (2019). Access to education for refugee and migrant children in Europe. https://data2.unhcr.org/en/documents/download/71202

UNICEF. (2009). Manual: Child friendly schools. https:/www.unicef.org/publications/files/ Child_Friendly_Schools_Manual_EN_040809.pdf

United Nations Convention on the Rights of the Child, November 20, 1989, https://www.refworld.org/docid/3ae6b38f0.html

United Nations. (2015). Transforming our world: The 2030 agenda for sustainable development. https://sustainabledevelopment.un.org/post2015/transformingourworld/publication

Westin, S. (2019). Ahlan Simsim: Helping children cope with the Syria crisis - SDG media zone, 74 UNGA. YouTube https://www.youtube.com/watch?v=zK_34qUBeT0

World Health Organization. (2018). Nurturing care for early childhood development: A framework for helping children survive and thrive to transform health and human potential. https://nurturing-care.org/

Notes

i Pseudonyms are used to protect the identity of the LR teachers. 